\title{
Pelvic fractures in severely injured elderly: a double-adjustment propensity score matched analysis from a level I trauma center
}

\author{
Shekhar Gogna ${ }^{1} \cdot$ Rifat Latifi' $^{2}$ - David J. Samson ${ }^{3} \cdot$ Jonathan Butler $^{4}$ \\ Received: 9 September 2020 / Accepted: 12 August 2021 / Published online: 25 August 2021 \\ ○) Springer-Verlag GmbH Germany, part of Springer Nature 2021
}

\begin{abstract}
Purpose Pelvic trauma has increased risk of mortality in the elderly. Our study aimed to analyze the impact of the additional burden of pelvic fractures in severely injured elderly.

Methods This is a retrospective analysis of a prospectively maintained trauma registry from 2012 to 2018 at an American College of Surgeons (ACS) verified Level I Trauma Center. Trauma patients aged $\geq 65$ years with ISS $\geq 16$ and AIS severity score $\geq 3$ in at least two body regions were divided in two groups: group I, consisted of elderly polytrauma patients without pelvic fractures, and group II elderly who had concomitant pelvic fractures. We used a double-adjustment method using propensity score matching (PSM) with subsequent covariate adjustment to minimize the effect of confounding factors, and give unbiased estimation of the impact of pelvic fractures. Balance assessment was conducted by computing absolute standardized mean differences (ASMDs) and ASMD $<0.10$ reflects good balance between groups.

Results Of 12,774 patients admitted during this time, 411 (3.2\%) elderly with a mean age of $77.75 \pm 8.32$ years met the inclusion criteria. Of this cohort, only 92 patients (22.4\%) had pelvic fractures. Females outnumbered males (55 vs. $45 \%$ ). Comparing characteristics of group I and group II using ASMDs, pelvic trauma patients were more likely to have higher systolic blood pressure (SBP), head injuries, lower extremity injuries, anticoagulant therapy, and cirrhosis. Fewer variables differed significantly after matching. We observed few instances of worse outcomes associated with pelvic trauma using PSM with and without covariate adjustment. Crude PSM without covariate adjustment, showed a significantly higher rate of deep vein thrombosis (DVT) for pelvic trauma $(p<0.001)$. Crude PSM also showed a significantly higher rate of ventilator-associated pneumonia (VAP) in group II ( $p=0.006)$. PSM with covariate adjustment did not confirm differences on these outcomes. PSM both without and with covariate adjustment found lower ventilator days and ICU length of stay among patients with pelvic trauma. No significant differences were seen on 12 outcomes: death, acute kidney injury (AKI), acute respiratory distress syndrome (ARDS), cardiac arrest with cardiopulmonary resuscitation (CPR), myocardial infarction (MI), pulmonary embolism (PE), unplanned intubation, unplanned admission to intensive care unit (ICU), catheter-associated urinary tract infection (CAUTI), and hospital length of stay.

Conclusions At a Level I Trauma Center the additional burden of pelvic fractures in seriously injured elderly did not translate into higher mortality. PSM without covariate adjustment suggests worse rates among pelvic trauma patients for DVT and VAP but covariate adjustment removed statistical significance for both outcomes. Pelvic trauma patients had shorter time on ventilator and in the ICU. Whether similar analytic methods applied to patients from larger data sources would produce similar findings remains to be seen.
\end{abstract}

Keywords Pelvic fractures $\cdot$ Elderly $\cdot$ Trauma $\cdot$ Outcomes $\cdot$ Propensity score matching $\cdot$ Confounders

\section{Introduction}

Pelvic trauma represents a substantial health risk to elderly people. The elderly comprise the largest growing segment

Rifat Latifi

Rifat.Latifi@wmchealth.org

Extended author information available on the last page of the article of the population worldwide and in the United States [1]. Trauma is the seventh leading cause of death in individuals 65 and older in the US (60,527 in 2019) [2]. Buller and 
colleagues [3] used the National Hospital Discharge Survey to estimate 103,310 pelvic ring fractures across all ages in 2007 in the US. Using the US Nationwide Inpatient Sample, there were approximately 32,700 new cases of pelvic fracture in the elderly in 2010 [4]. A study of a US military population during the period 2006-2015 estimated the incidence of pelvic ring fractures for those age $\geq 40$ years to be 26.0/100,000 person-years [5], while peak incidence was among those $<20$. Incidence has been noted to be bimodal, with a youth peak associated with high-energy mechanisms and an elderly surge linked to low-energy mechanisms [6]. Among other developed countries, incidence of pelvic fractures in the elderly varies considerably. In the Netherlands, Nanninga [7] estimated that the incidence rate of pelvic fractures in those $\geq 65$ in 2011 was $71.4 / 100,000$, while another Dutch study [8] reported a rate in this age stratum of 57.9/100,000 between 2008 and 2012. The former also noted increasing incidence between 1986 and 2011. In Spain, Prieto-Alhambra et al. [9] noted a similar rate across 2007-2009: 74.7/100,000. A study from Germany [10] found that the incidence of first inpatient pelvic fracture among individuals $\geq 60$ years was $165 / 100,000$ patient-years. In Australia, Boufous and associates [11] studied acute hospitals in New South Wales between 1999 and 2000, finding an incidence rate of 127.9/100,000 among individuals $\geq 65$.

Studies have found continuous age across adulthood to be an independent predictor of early mortality after pelvic trauma $[12,13]$. Separating adults into elderly and nonelderly, early mortality after pelvic trauma is higher in the elderly [8, 14-17]. Seven studies from the US report inhospital mortality rates between 5.7 and $20.4 \%$ [14-20]. Seven European studies cite in-hospital mortality rates ranging from 3.5 to $14.0 \%$ [21-27]. These studies have also addressed outcomes such as complications, ICU admission, pulmonary embolism, ICU length of stay, hospital length of stay, infections, acute respiratory distress syndrome (ARDS) and renal failure.

Few studies have compared pelvic trauma with non-pelvic trauma using matching techniques. Schulman [20] used data for blunt trauma patients seen at a US Level I Trauma Center, matching 1017 adult pelvic fractures with an equal number of non-pelvic fractures. Matching was based on a predictors-of-mortality model algorithm. These authors found pelvic ring fracture to be an independent predictor of mortality. Of two German studies, Almahmoud and coauthors [28] identified patients with severe blunt trauma from a Level I Trauma Center, matching 60 adult pelvic fracture patients with the same number without pelvic fracture on age, sex, and injury severity. ICU length of stay was higher in the pelvic fracture group. While Schulman and Almahmoud both selected adults of all ages, the matching study prior to ours that focused on the elderly was reported by Andrich et al. [29] These investigators used an insurance registry, selecting 5685 first pelvic fractures and 193,159 controls without pelvic fracture; all patients were $\geq 60$ years old. Controls were not limited to other types of trauma. Early mortality, adjusted for multiple confounders, was significantly higher for pelvic fracture. The current study uses double-adjustment propensity score analysis to determine whether elderly polytrauma patients with pelvic involvement have worse outcomes than those without pelvic trauma. Outcomes considered include: mortality, acute kidney injury (AKI), acute respiratory distress syndrome (ARDS), cardiac arrest with cardiopulmonary resuscitation (CPR), deep vein thrombosis (DVT), myocardial infarction (MI), pulmonary embolism (PE), unplanned intubation, unplanned ICU admission, severe sepsis, catheter-associated urinary tract infection (CAUTI), ventilator-associated pneumonia (VAP), ventilator days, ICU length of stay, and hospital length of stay.

\section{Methods}

\section{Study design}

This is a retrospective analysis of a prospectively maintained trauma registry at our Level I Trauma Center from 2012 to 2018. Approval for this study was provided by New York Medical College Institutional Review Board. The study population was divided into two groups; group I consisted of eligible patients without pelvic fractures and group II consisted of eligible patients with pelvic fractures.

\section{Inclusion criteria}

All elderly trauma patients aged 65 years and older with injury severity score (ISS) equal to or greater than 16 and AIS severity scores $\geq 3$ for at least two body regions.

\section{Exclusion criteria}

Trauma patients who are younger than 65 years, patients with no sign of life on arrival, with injury severity score (ISS) less than 16 and did not experience severe polytrauma.

\section{Variables and outcomes}

Patient demographic information collected included: age, race, sex, and body mass index (BMI). Injury-related data collected were systolic blood pressure (SBP), diastolic blood pressure (DBP), probability of survival (TRISS) score, and ISS on arrival. AIS severity scores $\geq 3$ were noted for the following body regions: abdomen, face, head, lower extremity, neck, unspecified, spine, thorax, and upper extremity. Patient medical comorbidities included: advanced directive 
limiting care, alcohol abuse, anticoagulant therapy, bleeding disorder, receiving chemotherapy for cancer, congestive heart failure (CHF), cirrhosis, chronic obstructive pulmonary disease (COPD), cerebrovascular accident (CVA), dementia, diabetes mellitus (DM), functional dependency, hypertension, myocardial infarction (MI), mental/personality disorder, peripheral arterial disease (PAD), current smoking, and steroid use.

Data were collected on 15 outcomes: mortality, AKI, ARDS, cardiac arrest with CPR, DVT, MI, PE, unplanned intubation, unplanned ICU admission, severe sepsis, CAUTI, VAP, ventilator days, ICU length of stay, and hospital length of stay.

\section{Statistical analysis}

Summary statistics are presented as frequencies and proportions for categorical variables. Continuous data are presented as mean \pm standard deviation (SD). Data were compared using the Student's $t$ test for continuous variables. Chi-squared and Fischer's exact tests were used for categorical variables through contingency table analysis.

A propensity score model was developed by logistic regression with pelvic trauma as the dependent variable. Modeling began with 43 candidate variables. Simple or univariable regressions were performed for all independent variables and those with $p$ values $<0.2$ were candidate variables for multivariable modeling. Model selection was conducted by backward elimination, in which independent variables with the highest $p$ value were eliminated one at a time until all remaining variable $p$ values were significant at a $p<0.05$ level.

Propensity scores were produced from the predicted probabilities of this model. Pelvic trauma patients were matched with the nearest neighbor non-pelvic trauma patients using a tolerance of 0.18 . Seven cases (7.6\%) did not find a match so the total pelvic trauma sample consisted of 85 cases and the entire propensity score-matched cohort was 170 patients.

Balance assessment was conducted by computing absolute standardized mean differences (ASMDs) for both the pre-match and propensity score-matched (PSM) cohorts. ASMDs are presented for binary and continuous variables. An ASMD value of $<0.10$ reflects good between-group balance on a particular characteristic [30]. Variables with ASMDs $\geq 0.10$ were included in multivariable regression models to adjust for potential confounding. The method of combining PSM and covariate adjustment has been described as double-adjustment or doubly robust [31]. The analysis was conducted using SPSS 27 software (IBM, Inc., Armonk NY, USA). The study was reported according to the Strengthening the reporting of observational studies in epidemiology (STROBE) criteria.

\section{Results}

Of 12,774 patients admitted during the study period, 411(3.2\%) met the criteria. There were 319 patients in group I and 92 in group II before PSM. After PSM there were 85 patients in group I and 85 in group II.

\section{Basic demographics of the study population}

The mean age of study cohort was $77.75 \pm 8.32$ years, with males constituting the majority of the cohort (55.0\%, Table 1). Mean BMI was $25.22 \pm 8.44 \mathrm{~kg} / \mathrm{m}^{2}$ and mean DBP was $74.45 \pm 18.50 \mathrm{~mm} \mathrm{Hg}$. Mean SBP was $132.16 \pm 33.88 \mathrm{~mm} \mathrm{Hg}$ and mean ISS was $25.83 \pm 8.43$. Whites were the most frequent race $(81.0 \%)$ and the five most prevalent comorbidities were: hypertension (60.8\%), diabetes mellitus (21.2\%), dementia (10.9\%), bleeding disorder $(9.7 \%)$, and congestive heart failure $(8.0 \%)$. Current smokers represented $6.8 \%$. The most common body region with severe injury in our study population was thorax (72.5\%), followed by head (55.5\%), lower extremity (34.8\%), spine (26.5\%), abdomen (15.1\%), upper extremity (6.3\%), neck (4.9\%), face (1.7\%), and unspecified (1.7\%).

\section{Comparison of patient-related characteristics}

Table 1 also depicts the comparison between the two groups at different stages of analysis. Means and proportions were higher in group II in 39 of 43 variables. ASMDs were $\geq 0.20$ (larger between-group differences) and the excess was in group II for DBP, SBP, female sex, SPB $\geq 130 \mathrm{~mm} \mathrm{Hg}$, AIS face $\geq 3$, AIS head $\geq 3$, AIS lower extremity $\geq 3$, AIS unspecified $\geq 3$, anticoagulant therapy, and cirrhosis. Before and after PSM both groups were balanced in terms of BMI, race, severe injury to the abdomen, congestive heart failure, diabetes mellitus, and current smoker. The rates of good between-group balance (ASMD $<0.10$ ) were similar for pre-match and PSM cohorts. However, the mean ASMD among those $<0.10$ was smaller after matching $(0.038)$ than pre-match (0.048). In addition, there were fewer variables that differed significantly between groups after matching (DBP, SBP, ISS) than pre-match (DBP, SBP, female sex, $\mathrm{SBP} \geq 130 \mathrm{~mm} \mathrm{Hg}$, severe injury to the head and severe injury to the lower extremities). Overall, PSM resulted in a lower mean ASMD (0.136) than pre-match (0.164).

\section{Comparison of outcomes in two groups}

Regarding binary outcomes, Table $2 \mathrm{~A}$ shows results of crude chi-squared tests (without covariate adjustment) between groups I and II on 12 outcomes. Pre-match, deep vein 


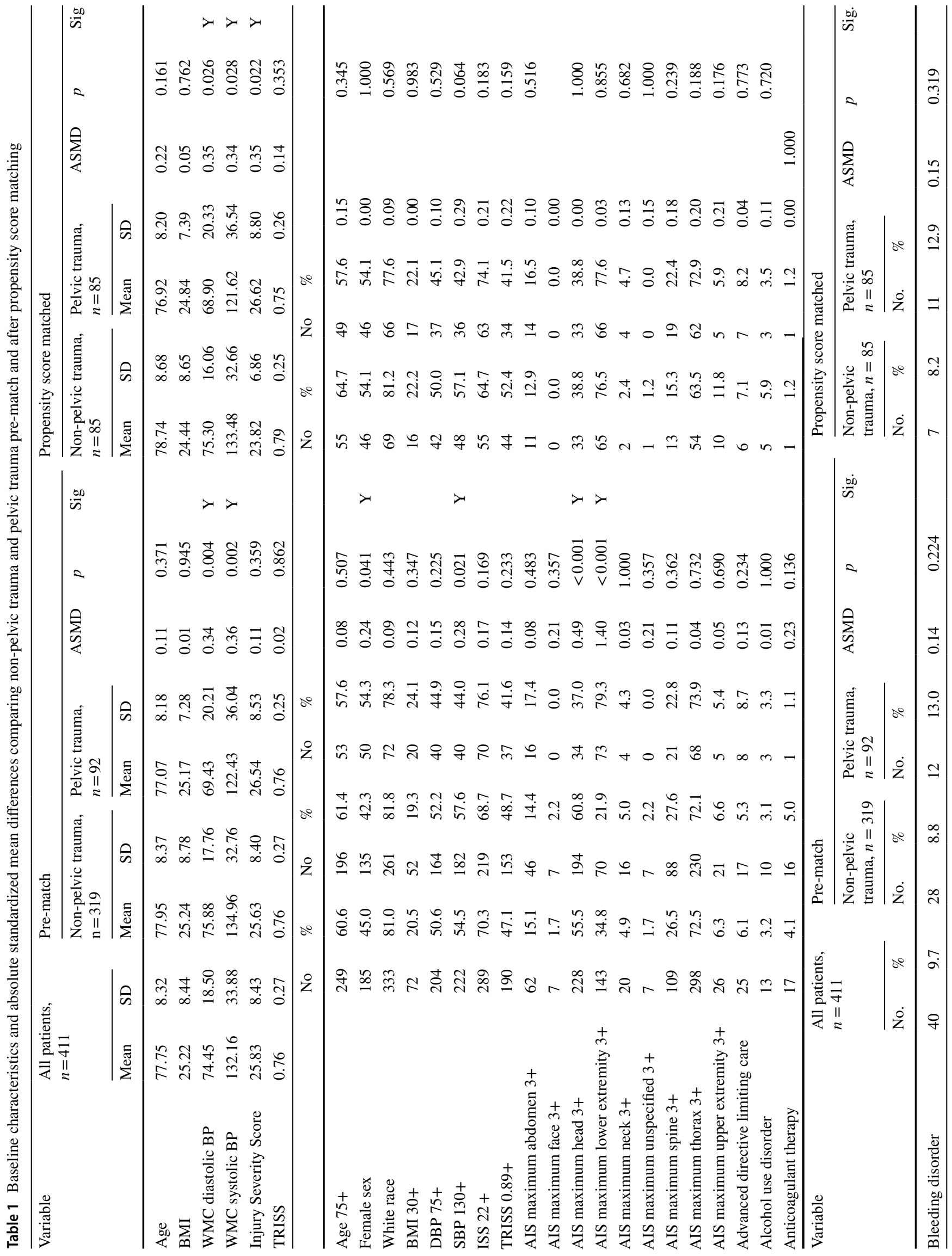




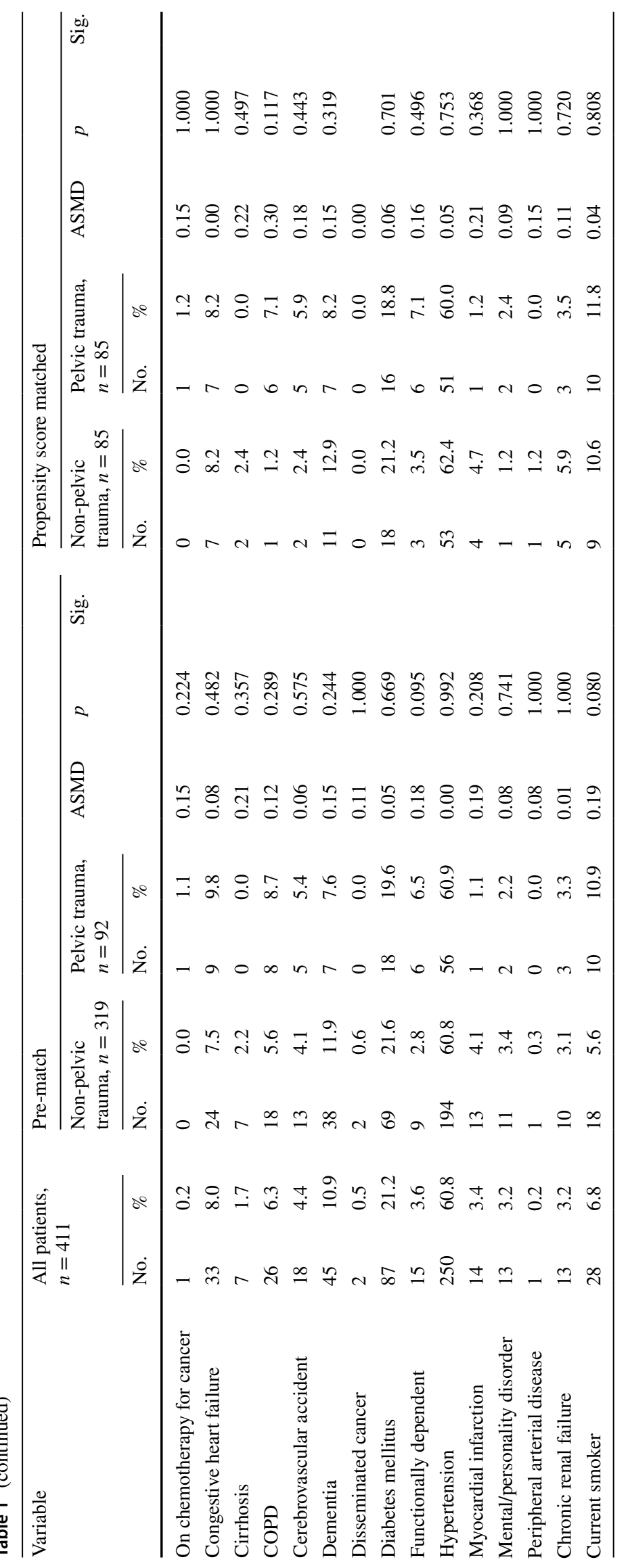


Table 2 Frequencies (A) and odds ratios (B) of binary outcomes for non-pelvic trauma compared with pelvic trauma, by pre-match, propensity score matched, and propensity score matched with covariate adjustment

\begin{tabular}{|c|c|c|c|c|c|c|c|c|c|c|c|c|c|c|c|c|}
\hline \multicolumn{17}{|l|}{ A } \\
\hline \multirow{3}{*}{\multicolumn{3}{|c|}{ Outcome }} & \multicolumn{7}{|c|}{ Crude, pre-match } & \multicolumn{7}{|c|}{ Crude, propensity score matched } \\
\hline & & & \multicolumn{2}{|c|}{$\begin{array}{l}\text { No pelvic } \\
\text { trauma }\end{array}$} & \multicolumn{2}{|c|}{$\begin{array}{l}\text { Pelvic } \\
\text { trauma }\end{array}$} & \multirow{2}{*}{\multicolumn{2}{|c|}{$p$}} & \multirow[t]{2}{*}{ Sig } & \multicolumn{2}{|c|}{$\begin{array}{l}\text { No pelvic } \\
\text { trauma }\end{array}$} & \multicolumn{2}{|c|}{$\begin{array}{l}\text { Pelvic } \\
\text { trauma }\end{array}$} & \multirow{2}{*}{\multicolumn{2}{|c|}{$p$}} & \multirow[t]{2}{*}{ Sig } \\
\hline & & & No & $\%$ & No & $\%$ & & & & No & $\%$ & No & $\%$ & & & \\
\hline \multicolumn{3}{|l|}{ Death } & 12 & 3.8 & 3 & 3.3 & & 1.000 & & 1 & 1.3 & 3 & & 3.8 & 1.000 & \\
\hline \multicolumn{3}{|l|}{ Acute kidney injury (AKI) } & 20 & 6.3 & 7 & 7.6 & & 0.648 & & 8 & 10.1 & 6 & & 7.6 & 0.648 & \\
\hline \multicolumn{3}{|l|}{ Acute respiratory distress syndrome (ARDS) } & 44 & 13.8 & 10 & 10.9 & & 0.465 & & 15 & 19.0 & 10 & 12 & 2.7 & 0.465 & \\
\hline \multicolumn{3}{|l|}{ Cardiac arrest with CPR } & 16 & 5.0 & 5 & 5.4 & & 0.872 & & 4 & 5.1 & 5 & & 5.3 & 0.872 & \\
\hline \multicolumn{3}{|l|}{ Deep vein thrombosis (DVT) } & 1 & 0.3 & 8 & 8.7 & & $<0.001$ & $\mathrm{Y}$ & 0 & 0.0 & 7 & & 3.9 & $<0.001$ & $\mathrm{Y}$ \\
\hline \multicolumn{3}{|l|}{ Myocardial infarction (MI) } & 8 & 2.5 & 3 & 3.3 & & 0.715 & & 4 & 5.1 & 2 & & 2.5 & 0.715 & \\
\hline \multicolumn{3}{|l|}{ Pulmonary embolism (PE) } & 4 & 1.3 & 3 & 3.3 & & 0.190 & & 0 & 0.0 & 2 & & 2.5 & 0.190 & \\
\hline \multicolumn{3}{|l|}{ Unplanned intubation } & 24 & 7.5 & 5 & 5.4 & & 0.491 & & 7 & 8.9 & 4 & & 5.1 & 0.491 & \\
\hline \multicolumn{3}{|l|}{ Unplanned admission to ICU } & 13 & 4.1 & 5 & 5.4 & & 0.575 & & 2 & 2.5 & 3 & & 3.8 & 0.575 & \\
\hline \multicolumn{3}{|l|}{ Severe sepsis } & 17 & 5.3 & 3 & 3.3 & & 0.585 & & 6 & 7.6 & 3 & & 3.8 & 0.585 & \\
\hline \multicolumn{3}{|c|}{ Catheter associated urinary tract infection (CAUTI) } & 10 & 3.1 & 5 & 5.4 & & 0.300 & & 2 & 2.5 & 4 & & 5.1 & 0.300 & \\
\hline \multicolumn{3}{|l|}{ Ventilator-associated pneumonia (VAP) } & 6 & 1.9 & 7 & 7.6 & & 0.006 & $6 \mathrm{Y}$ & 1 & 1.3 & 4 & & 5.1 & 0.006 & $\mathrm{Y}$ \\
\hline \multicolumn{17}{|l|}{ B } \\
\hline Outcome & Crude, & pre-m & natch & & & & $\begin{array}{l}\text { Crud } \\
\text { matcl }\end{array}$ & $\begin{array}{l}\text { de, prope } \\
\text { hed }\end{array}$ & ensity s & core & & $\begin{array}{l}\text { Proper } \\
\text { covari }\end{array}$ & $\begin{array}{l}\text { ensity s } \\
\text { iate ad }\end{array}$ & $\begin{array}{l}\text { score ma } \\
\text { ljustmen }\end{array}$ & latched w & \\
\hline & OR & $95 \mathrm{~L}$ & $95 \mathrm{U}$ & $p$ & & Sig & OR & $95 \mathrm{~L}$ & $95 \mathrm{U}$ & $p$ & Sig & OR & $95 \mathrm{~L}$ & $95 \mathrm{U}$ & $p$ & Sig \\
\hline Death & 0.86 & 0.24 & 3.12 & 12 & 1.000 & & 3.08 & 0.31 & 30.26 & 0.620 & & 9.73 & 0.37 & 254.22 & 20.172 & \\
\hline Acute kidney injury (AKI) & 1.23 & 0.50 & 3.0 & 01 & 0.648 & & 0.73 & 0.24 & 2.21 & 0.576 & & 0.87 & 0.19 & 3.90 & 0.854 & \\
\hline $\begin{array}{l}\text { Acute respiratory distress syndrome } \\
\text { (ARDS) }\end{array}$ & 0.76 & 0.37 & 1.58 & 58 & 0.465 & & 0.62 & 0.26 & 1.48 & 0.276 & & 0.40 & 0.13 & 1.25 & 50.116 & \\
\hline Cardiac arrest with CPR & 1.09 & 0.39 & 3.0 & 05 & 0.794 & & 1.27 & 0.33 & 4.90 & 1.000 & & 1.34 & 0.26 & 6.80 & 0.727 & \\
\hline Deep vein thrombosis (DVT) & 30.29 & 3.74 & 245.5 & & $<0.001$ & & & & & & & & & & & \\
\hline Myocardial infarction (MI) & 1.31 & 0.34 & 5.0 & 04 & 0.715 & & 0.49 & 0.09 & 2.74 & 0.681 & & 0.30 & 0.03 & 2.63 & $\begin{array}{ll}3 & 0.278\end{array}$ & \\
\hline Pulmonary embolism (PE) & 2.65 & 0.58 & 12.08 & & 0.190 & & & & & & & & & & & \\
\hline Unplanned intubation & 0.71 & 0.26 & 1.9 & 91 & 0.491 & & 0.55 & 0.15 & 1.95 & 0.348 & & 0.45 & 0.10 & 2.10 & $0 \quad 0.313$ & \\
\hline Unplanned admission to ICU & 1.35 & 0.47 & 3.90 & 90 & 0.567 & & 1.52 & 0.25 & 9.35 & 1.000 & & 4.50 & 0.25 & 80.94 & 0.307 & \\
\hline Severe sepsis & 0.60 & 0.17 & 2.0 & 09 & 0.585 & & 0.48 & 0.12 & 1.99 & 0.495 & & 0.04 & 0.00 & 0.90 & 0.042 & $\mathrm{Y}$ \\
\hline $\begin{array}{l}\text { Catheter associated urinary tract infec- } \\
\text { tion (CAUTI) }\end{array}$ & 1.78 & 0.59 & 5.3 & 33 & 0.342 & & 2.05 & 0.37 & 11.55 & 0.681 & & 0.72 & 0.05 & 9.49 & 90.800 & \\
\hline Ventilator-associated pneumonia (VAP) & 4.30 & 1.41 & 13.12 & & 0.012 & & 4.16 & 0.45 & 38.08 & 0.367 & & 4.45 & 0.22 & 88.14 & $4 \quad 0.327$ & \\
\hline
\end{tabular}

thrombosis (DVT) was significantly more frequent in group II $(8.7 \%)$ than in group I $(0.3 \%, p<0.001)$. Ventilator-associated pneumonia (VAP) was also significantly more common in group II (7.6\%) than group I $(1.9 \%, p=0.006)$. Groups did not differ on: death, AKI, ARDS, cardiac arrest with CPR, MI, PE, unplanned intubation, unplanned admission to ICU, severe sepsis, and CAUTI. Similar findings were observed for crude analysis of PSM results. DVT was seen in $8.9 \%$ of group II and $0.0 \%$ of group I $(p<0.001)$. VAP occurred in $5.1 \%$ of group II and $1.3 \%$ of group I $(p=0.006)$. All other outcomes in the PSM cohort did not significantly differ between groups.
A similar pattern of results was observed by conducting logistic regressions (Table 2B). Crude (simple or univariable) regression of the pre-match cohort found a significant increase in odds of DVT (OR 30.29, 95\% CI 3.74-245.52, $p<0.001)$. In the PSM cohort, regressions failed because of zero events in group I. Thus, it is unclear whether further control of confounding would still find worse rates of DVT. Crude regression of VAP showed significantly increased odds in group II (OR 4.30, 95\% CI 1.41-13.12, $p=0.012$ ). Although similar magnitude ORs were found for crude PSM (OR 4.16, 95\% CI 0.45-38.08, $p=0.367$ ) and PSM with covariate adjustment (OR 4.45, 95\% CI 0.22-88.14, 
$p=0.327)$, results did not achieve statistical significance. Further, as confounding was taken into account through PSM without and with covariate adjustment, 95\% CIs around ORs became wider, suggesting greater uncertainty around the independent influence of pelvic trauma on the odds of VAP. No significant regression results were found for death, AKI, CPR, MI, PE, unplanned intubation, unplanned admission to ICU and CAUTI. Severe sepsis was significantly less likely in group II (OR 0.04, 95\% CI 0.00-0.90, $p=0.042$ ).

Analysis of continuous outcomes showed significantly lower mean ventilator days in group II $(0.22 \pm 0.95)$ versus group I $(1.60 \pm 6.47, p<0.001$, Table $3 \mathrm{~A})$ in the crude pre-match cohort. In the crude PSM analysis, the difference between means was greater (group II: $0.25 \pm 1.02$; group I: $3.51 \pm 11.00, p=0.011$ ). Mean ICU days were also significantly lower in crude pre-match (group II $1.03 \pm 2.05$, group I $2.31 \pm 5.69, p=0.001$ ) and crude PSM (group II $1.08 \pm 2.18$, group I $3.69 \pm 8.02, p=0.007$ ) analyses. Crude analysis of mean hospital length of stay did not show significant between-group differences in the pre-match or PSM cohorts. Linear regressions showed lower ventilator days on all three analyses: crude pre-match $(\beta-1.38,95 \% \mathrm{CI}-2.74$ to $-0.02, p=0.047)$, crude PSM $(\beta-3.26,95 \% \mathrm{CI}-5.77$ to $-0.76, p=0.011$ ) and PSM with covariate adjustment $(\beta-2.65,95 \%$ CI -5.26 to $-0.04, p=0.046)$. The same pattern held for ICU days: crude pre-match $(\beta-1.27,95 \%$ CI -2.50 to $-0.04, p=0.043)$, crude PMS $(\beta-2.61,95 \%$ CI -4.52 to $-0.71, p=0.008)$ and PSM with covariate adjustment $(\beta-2.33,95 \% \mathrm{CI}-4.28$ to $-0.38, p=0.019)$. None of the regressions on hospital length of stay produced significant results regarding pelvic trauma.

\section{Discussion}

This study, conducted at our Level I Trauma Center, used a novel approach to control for confounding to compare elderly polytrauma pelvic trauma patients with those lacking pelvic trauma on 15 outcomes. Considering both prematch and PSM data sets, systolic and diastolic blood pressure were lower in the pelvic trauma group. The PSM data showed higher mean ISS in group II. Degree of balance between groups was better after PSM and covariate adjustment was conducted to control for remaining imbalances. Crude PSM without covariate adjustment, by contingency table analysis, showed a significantly higher rate of DVT for pelvic trauma. PSM without and with covariate adjustment analyses were not possible due to zero events group I, thus evidence is lacking from analyses controlling for confounding. PSM contingency table analysis showed a significantly higher rate of VAP in group II. When there are attempts to control for confounding by PSM, both without and with covariate adjustment, there are wider nonsignificant $95 \%$ CIs and thus greater uncertainty surrounding estimates of association between pelvic trauma and VAP. Analysis using the most robust method of controlling for confounding, PSM with covariate adjustment, did not find significantly worse results in the pelvic trauma group for VAP or any other outcome. Rather than showing worse outcomes associated with pelvic trauma, analyses using PSM with covariate adjustment found only three significant between-group differences, each favoring the pelvic trauma group, on severe sepsis, ventilator days, and ICU stay. Analyses produced nonsignificant differences for these 12 outcomes: death, AKI, ARDS,

Table 3 Means (A) and linear regression coefficients (B) of continuous outcomes for non-pelvic trauma compared with pelvic trauma, by prematch, propensity score matched, and propensity score matched with covariate adjustment

\begin{tabular}{|c|c|c|c|c|c|c|c|c|c|c|c|c|c|c|c|c|c|c|}
\hline \multicolumn{19}{|l|}{ A } \\
\hline \multirow[t]{3}{*}{ Outcome } & \multicolumn{9}{|c|}{ Crude, pre-match } & \multicolumn{9}{|c|}{ Crude, propensity score matched } \\
\hline & \multicolumn{3}{|c|}{ Non-pelvic trauma } & \multicolumn{3}{|c|}{ Pelvic trauma } & \multirow{2}{*}{\multicolumn{2}{|c|}{$p$}} & \multirow[t]{2}{*}{ Sig } & \multicolumn{4}{|c|}{ Non-pelvic trauma } & \multicolumn{3}{|c|}{ Pelvic trauma } & \multirow[t]{2}{*}{$p$} & \multirow[t]{2}{*}{$\mathrm{Sig}$} \\
\hline & $\mathrm{N}$ & $\mathrm{Mn}$ & $\mathrm{SD}$ & $\mathrm{N}$ & $\mathrm{Mn}$ & $\mathrm{S}$ & & & & $\mathrm{N}$ & $\mathrm{Mn}$ & SD & & $\mathrm{N}$ & $\mathrm{Mn}$ & SD & & \\
\hline Ventilator days & 312 & 1.60 & 6.47 & 88 & 0.22 & & 95 & $<0.001$ & $\mathrm{Y}$ & 78 & 3.51 & 11. & & 76 & 0.25 & 1.02 & 0.011 & $\mathrm{Y}$ \\
\hline ICU days & 308 & 2.31 & 5.69 & 86 & 1.03 & & 05 & 0.001 & $\mathrm{Y}$ & 78 & 3.69 & 8. & 02 & 74 & 1.08 & 2.18 & 0.007 & $\mathrm{Y}$ \\
\hline Hospital LOS & 315 & 6.39 & 9.41 & 90 & 4.96 & & 38 & 0.066 & & 78 & 8.24 & 13. & & 78 & 5.05 & 5.72 & 0.058 & \\
\hline \multicolumn{19}{|l|}{ B } \\
\hline \multirow[t]{2}{*}{ Outcome } & \multicolumn{6}{|c|}{ Crude, pre-match } & \multicolumn{6}{|c|}{ Crude, propensity score matched } & \multicolumn{6}{|c|}{$\begin{array}{l}\text { Propensity score matched with covariate } \\
\text { adjustment }\end{array}$} \\
\hline & $\beta$ & $95 \mathrm{~L}$ & $95 \mathrm{U}$ & & $p$ & Sig & $\beta$ & $95 \mathrm{~L}$ & 95 & & $p$ & Sig & $\beta$ & & $95 \mathrm{~L}$ & $95 \mathrm{U}$ & $p$ & Sig \\
\hline Ventilator days & -1.38 & -2.74 & -0.02 & & 0.047 & $\mathrm{Y}$ & -3.26 & -5.77 & & .76 & 0.011 & $\mathrm{Y}$ & & .65 & -5.26 & -0.04 & 0.046 & Y \\
\hline ICU days & -1.27 & -2.50 & -0.04 & & 0.043 & $\mathrm{Y}$ & -2.61 & -4.52 & & .71 & 0.008 & $\mathrm{Y}$ & & 2.33 & -4.28 & -0.38 & 0.019 & $\mathrm{Y}$ \\
\hline Hospital LOS & -1.43 & -3.47 & 0.61 & & 0.168 & & -3.19 & -6.48 & 0.1 & & 0.057 & & & & -6.03 & 0.96 & 0.154 & \\
\hline
\end{tabular}


cardiac arrest with CPR, MI, PE, unplanned intubation, unplanned admission to ICU, CAUTI, and hospital length of stay. These findings conflict with other results in the literature suggesting worse outcomes for patients with pelvic trauma. Event rates for both groups were low in our study for most outcomes, so replicating studies with larger numbers would be useful. With respect to mortality, the small absolute number of deaths observed in crude pre-match, crude PSM, and PSM with covariate adjustment analyses indicate that our findings should be interpreted with caution. Given these caveats, it is unclear whether clinical practice should be altered based on these findings.

To our knowledge, only one other study of elderly pelvic trauma has used matching plus covariate adjustment to control for confounding [29]. Our study differs from the Andrich study in several ways. Andrich study pelvic fracture patients were not limited by injury severity (including both minor and major pelvic fractures) but ours were characterized by severe polytrauma (AIS severity score $\geq 3$ for at least two body regions). While we used elderly polytrauma control patients without pelvic trauma, Andrich used controls who were not limited to trauma cases. Andrich used age, sex, index case, and month for matching then ran Cox regression covariate adjustment while we used PSM and logistic regression covariate adjustment. Andrich used a German insurance registry administrative data for about 200,000 individuals (about 1:34 matching) and our project focused on a single Level I Trauma Center with 411 patients (1:1 matching for 170). The Andrich study had a high level of statistical power for analyzing a single outcome; however, our study had lower power for analyzing 15 outcomes.

It is important to compare population characteristics of our series and the two German studies that also used matching techniques to control for confounding. The Andrich study [29] of elderly pelvic trauma cases and controls not limited to injury did not report results in a manner that makes comparisons possible. The Almahmoud study [28] of 120 adult patients with ISS $\geq 16$ from the University of Aachen (not limited to polytrauma) reported a similar pattern of more chest injuries than abdomen injuries (chest/ abdomen Aachen: 58.3/27.5\%; our series: 72.5/15.1\%) Mean ISS was about 27 for Almahmoud and about 26 for us and both included a majority of males. A 2020 report from the Trauma Register (TR)of the German Trauma Society (DGU) [32] also reported that adult trauma patients with ISS $\geq 16$ and a least one physical problem had head injury in $63.8 \%$ (compared with 55.5 for us), thorax injury in $51.4 \%$ (72.5\% for us) and abdomen injury in $14.2 \%$ (15.1\% for us). Mean ISS in this TR-DGU group was about 29, versus 26 for us and both data sources were majority male.

Pelvic fractures in severely injured polytrauma elderly require multidisciplinary trauma care. There is evidence in favor of the management of the pelvic fracture patients at Level I Trauma Centers as they are associated with decreased in-hospital and early mortality $[16,33]$. In addition to the ACS level of the trauma center, hospital volume also plays an important part in enhancing the outcomes after pelvic injures [34]. We strongly believe that the trauma surgeons, orthopedics, interventional radiology, and geriatricians together as a team will enhance the outcomes after severe polytrauma in the elderly. These factors may explain the low mortality rate $(3.3 \%)$ among elderly polytrauma patients with pelvic fractures we observed in this study.

Our study has several strengths: we used a robust method of controlling for confounding involving PSM and covariate adjustment. This study was able to take into account the contribution of associated injuries. There are a few inherent limitations of the study. This single-center study is a retrospective analysis and has a small sample size with low event rates. The data on high-energy vs low-energy mechanisms, operative variables, and details of the anatomic distribution of fracture pattern were not completely available from our trauma registry. Perhaps if such data had been obtained, we may have found an explanation for the significantly shorter ICU stay observed in the pelvic trauma group. One practical limitation of this study is that the results are dependent on the accuracy of data entry into the electronic medical record and our trauma registry. The most effective treatment regimen is a point of controversy and often depends upon the availability, timing, and experience with these different treatment modalities. Our study did not perform comparisons between elderly and younger adult cohorts, so we are unable to draw conclusions regarding pelvic trauma across age groups. The Schulman study [20] found that both age $>65$ years and pelvic fracture were independent predictors of mortality, but it is unclear if there was an age by pelvic trauma interaction (whether higher mortality in pelvic trauma was present in elderly but not younger ages).

\section{Conclusion}

At a level I trauma center the additional burden of pelvic fractures in seriously injured elderly did not translate into higher mortality. PSM without covariate adjustment suggests worse rates among pelvic trauma patients for DVT and VAP but covariate adjustment removed statistical significance for both outcomes. Pelvic trauma patients had shorter time on ventilator and in the ICU. Whether similar analytic methods applied to patients from larger data sources would produce similar findings remains to be seen.

Author contributions SG: manuscript, statistical analysis, and data collection. RL: study conceptualization, design, critical revision, and overall supervision. DJS: manuscript, statistical analysis, and data collection. JB: manuscript, statistical analysis, and data collection. 
Funding Not applicable.

Availability of data and material The data that support the findings of this study are available from the corresponding author, RL, upon reasonable request.

\section{Declarations}

Conflict of interest Shekhar Gogna, Rifat Latifi, David Samson, and Jonathan Butler declare that they have no conflict of interest.

Ethics approval This study was conducted with IRB approval from the New York Medical College (L\#12, 991).

Consent to participate Not applicable.

Consent for publication Not applicable.

Code availability Not applicable.

\section{References}

1. A Profile of Older Americans: 2010. https://acl.gov/sites/default/ files/Aging\%20and\%20Disability\%20in\%20America/2010profile. pdf. Accessed 17 Mar 2020

2. Underlying Cause of Death 1999-2019 on CDC WONDER Online Database. Published online 2020. http://wonder.cdc.gov/ ucd-icd10.html. Accessed January 28, 2021

3. Buller LT, Best MJ, Quinnan SM. A Nationwide analysis of pelvic ring fractures: incidence and trends in treatment, length of stay, and mortality. Geriatr Orthop Surg Rehabil. 2016;7(1):9-17. https://doi.org/10.1177/2151458515616250.

4. Sullivan MP, Baldwin KD, Donegan DJ, Mehta S, Ahn J. Geriatric fractures about the hip: divergent patterns in the proximal femur, acetabulum, and pelvis. Orthopedics. 2014;37(3):151-7. https:// doi.org/10.3928/01477447-20140225-50.

5. Pisquiy JJ, Carter JT, Chan A, Kusnezov N, Adler A. Incidence of pelvic ring fractures in the U.S. military population. Cureus. 2020;12(2): e6899. https://doi.org/10.7759/cureus.6899.

6. Brown JV, Yuan S. Traumatic injuries of the pelvis. Emerg Med Clin North Am. 2020;38(1):125-42. https://doi.org/10.1016/j. emc.2019.09.011.

7. Nanninga GL, de Leur K, Panneman MJM, van der Elst M, Hartholt KA. Increasing rates of pelvic fractures among older adults: The Netherlands, 1986-2011. Age Ageing. 2014;43(5):648-53. https://doi.org/10.1093/ageing/aft212.

8. Verbeek DO, Ponsen KJ, Fiocco M, Amodio S, Leenen LPH, Goslings JC. Pelvic fractures in the Netherlands: epidemiology, characteristics and risk factors for in-hospital mortality in the older and younger population. Eur J Orthop Surg Traumatol Orthop Traumatol. 2018;28(2):197-205. https://doi.org/10.1007/ s00590-017-2044-3.

9. Prieto-Alhambra D, Avilés FF, Judge A, et al. Burden of pelvis fracture: a population-based study of incidence, hospitalisation and mortality. Osteoporos Int J Establ Result Coop Eur Found Osteoporos Natl Osteoporos Found USA. 2012;23(12):2797-803. https://doi.org/10.1007/s00198-012-1907-z.

10. Andrich S, Haastert B, Neuhaus E, et al. Epidemiology of pelvic fractures in Germany: considerably high incidence rates among older people. PLoS ONE. 2015;10(9): e0139078. https://doi.org/ 10.1371/journal.pone. 0139078 .
11. Boufous S, Finch C, Lord S, Close J. The increasing burden of pelvic fractures in older people, New South Wales, Australia. Injury. 2005;36(11):1323-9. https://doi.org/10.1016/j.injury.2005.02. 008.

12. Wang H, Phillips JL, Robinson RD, et al. Predictors of mortality among initially stable adult pelvic trauma patients in the US: data analysis from the national trauma data bank. Injury. 2015;46(11):2113-7. https://doi.org/10.1016/j.injury.2015.08. 039.

13. O'Brien DP, Luchette FA, Pereira SJ, et al. Pelvic fracture in the elderly is associated with increased mortality. Surgery. 2002;132(4):710-4. https://doi.org/10.1067/msy.2002.127690 (discussion 714-715).

14. Matityahu A, Elson J, Morshed S, Marmor M. Survivorship and severe complications are worse for octogenarians and elderly patients with pelvis fractures as compared to adults: data from the national trauma data bank. J Osteoporos. 2012;2012: 475739. https://doi.org/10.1155/2012/475739.

15. Dechert TA, Duane TM, Frykberg BP, Aboutanos MB, Malhotra AK, Ivatury RR. Elderly patients with pelvic fracture: interventions and outcomes. Am Surg. 2009;75(4):291-5. https://doi.org/ 10.1177/000313480907500405.

16. Keil DS, Gross S, Seymour RB, Sims S, Karunakar MA. Mortality after high-energy pelvic fractures in patients of age 65 years or older. J Orthop Trauma. 2018;32(3):124-8. https://doi.org/10. 1097/BOT.0000000000001041.

17. Henry SM, Pollak AN, Jones AL, Boswell S, Scalea TM. Pelvic fracture in geriatric patients: a distinct clinical entity. J Trauma. 2002;53(1):15-20. https://doi.org/10.1097/00005373-20020 7000-00004.

18. Garcia M, Firek M, Zakhary B, Brenner M, Hildebrand F, Coimbra R. Severe pelvic fracture in the elderly: high morbidity, mortality, and resource utilization. Am Surg. 2020;86(10):1401-6. https://doi.org/10.1177/0003134820964493.

19. Bible JE, Kadakia RJ, Wegner A, Richards JE, Mir HR. Oneyear mortality after isolated pelvic fractures with posterior ring involvement in elderly patients. Orthopedics. 2013;36(6):760-4. https://doi.org/10.3928/01477447-20130523-21.

20. Schulman JE, O'Toole RV, Castillo RC, et al. Pelvic ring fractures are an independent risk factor for death after blunt trauma. J Trauma. 2010;68(4):930-4. https://doi.org/10.1097/TA.0b013 e3181cb49d1.

21. Arden N, Richette P, Cooper C, et al. Can we identify patients with high risk of osteoarthritis progression who will respond to treatment? A focus on biomarkers and frailty. Drugs Aging. 2015;32(7):525-35. https://doi.org/10.1007/s40266-015-0276-7.

22. Höch A, Özkurtul O, Pieroh P, Josten C, Böhme J. Outcome and 2-year survival rate in elderly patients with lateral compression fractures of the pelvis. Geriatr Orthop Surg Rehabil. 2017;8(1):39. https://doi.org/10.1177/2151458516681142.

23. Osterhoff G, Noser J, Held U, Werner CML, Pape H-C, Dietrich M. Early operative versus nonoperative treatment of fragility fractures of the pelvis: a propensity-matched multicenter study. J Orthop Trauma. 2019;33(11):e410-5. https://doi.org/10.1097/ BOT.0000000000001584.

24. Rollmann MF, Herath SC, Braun BJ, et al. In-hospital mortality of pelvic ring fractures in older adults now and then: a pelvic registry study. Geriatr Gerontol Int. 2019;19(1):24-9. https://doi.org/10. 1111/ggi.13558.

25. Schmitz P, Lüdeck S, Baumann F, Kretschmer R, Nerlich M, Kerschbaum M. Patient-related quality of life after pelvic ring fractures in elderly. Int Orthop. 2019;43(2):261-7. https://doi.org/ 10.1007/s00264-018-4030-8.

26. Ojodu I, Pohlemann T, Hopp S, Rollmann MFR, Holstein JH, Herath SC. Predictors of mortality for complex fractures of the pelvic ring in the elderly: a twelve-year review from a German 
level I trauma center. Injury. 2015;46(10):1996-8. https://doi.org/ 10.1016/j.injury.2015.07.034.

27. Hermans E, Edwards MJR, Goslings JC, Biert J. Open pelvic fracture: the killing fracture? J Orthop Surg. 2018;13(1):83. https:// doi.org/10.1186/s13018-018-0793-2.

28. Almahmoud K, Pfeifer R, Al-Kofahi K, et al. Impact of pelvic fractures on the early clinical outcomes of severely injured trauma patients. Eur J Trauma Emerg Surg Off Publ Eur Trauma Soc. 2018;44(2):155-62. https://doi.org/10.1007/s00068-016-0754-6.

29. Andrich S, Haastert B, Neuhaus E, et al. Excess mortality after pelvic fractures among older people. J Bone Miner Res Off J Am Soc Bone Miner Res. 2017;32(9):1789-801. https://doi.org/10. 1002/jbmr.3116.

30. Austin PC. Balance diagnostics for comparing the distribution of baseline covariates between treatment groups in propensity-score matched samples. Stat Med. 2009;28(25):3083-107. https://doi. org/10.1002/sim.3697.

31. Nguyen T-L, Collins GS, Spence J, et al. Double-adjustment in propensity score matching analysis: choosing a threshold

\section{Authors and Affiliations}

\section{Shekhar Gogna ${ }^{1} \cdot$ Rifat Latifi ${ }^{2}$ D . David J. Samson ${ }^{3}$. Jonathan Butler ${ }^{4}$}

Shekhar Gogna

Shekhar.gogna@wmchealth.org

David J. Samson

david.samson@wmchealth.org

Jonathan Butler

jonathan.butler@wmchealth.org

1 Department of Surgery, Westchester Medical Center, New York Medical College, 100 Woods Road, Taylor Pavilion, E-348, Valhalla, NY 10595, USA for considering residual imbalance. BMC Med Res Methodol. 2017;17(1):78. https://doi.org/10.1186/s12874-017-0338-0.

32. Annual Report 2020. Committee on emergency medicine, intensive care and trauma management of the German Trauma Society (DGU). Published online 2020. http://www.traumaregister-dgu. de/fileadmin/user_upload/traumaregister-dgu.de/docs/Downloads/ TR-DGU_Annual_report_2020.pdf. Accessed 23 Apr 2021

33. Oliphant BW, Tignanelli CJ, Napolitano LM, Goulet JA, Hemmila MR. American College of Surgeons Committee on Trauma verification level affects trauma center management of pelvic ring injuries and patient mortality. J Trauma Acute Care Surg. 2019;86(1):1-10. https://doi.org/10.1097/TA.0000000000002062.

34. Genuario J, Koval KJ, Cantu RV, Spratt KF. Does hospital surgical volume affect in-hospital outcomes in surgically treated pelvic and acetabular fractures? Bull NYU Hosp Jt Dis. 2008;66(4):282-9.
2 Westchester Medical Center, New York Medical College, School of Medicine, Valhalla, NY 10595, USA

3 Department of Surgery, Clinical Research Unit, Westchester Medical Center, 100 Woods Road, Taylor Pavilion, Office E-348, Valhalla, NY 10595, USA

4 Clinical Research Unit, Westchester Medical Center, 100 Woods Road, Taylor Pavilion, Office E-348, Valhalla, NY 10595, USA 